\title{
Education as Reconstruction. School Typology in Post-earthquake Reconstruction in Central Italy
}

\author{
Enrico Bordogna and Tommaso Brighenti
}

\begin{abstract}
The text investigates the role of education and school typology in reconstruction strategies in the different settlement and socio-economic contexts of Central Italy affected by the 2016 earthquake.
\end{abstract}

Keywords Earthquake reconstruction $\cdot$ School typology $\cdot$ Norcia $\cdot$ Amatrice Camerino

In keeping with the long case history of earthquakes in Italy (Messina 1908; Belice 1968; Friuli 1976; L'Aquila 2009; Romagna 2014), the earthquake that struck the territories of Central Italy in the Summer-Autumn of 2016 caused damages on many different fronts: to monuments, to the urban residential fabric, to scattered private buildings, to production facilities, to the school and services systems, to the road and access networks, and so on.

In all these areas, beyond the necessary distinction between the time of the emergency, to be tackled with rapid reversible interventions, and that of the reconstruction, which, on the contrary, requires thoughtful and prospectively stable interventions aimed at restoring and relaunching the form and life of the cities and territories affected, the reconstruction strategy can be, and has been, variable.

If, for example, in the case of the Friuli earthquake, the reconstruction tended to favour precise individual interventions in order to revive the production activity and the reconstitution of a residential fabric certainly not "as it was and where it was", but conforming to the morphology and the characteristics existing prior to the earthquake; and if in the case of the Belice earthquake, the appraisal can only be varied but was, on the whole, positive, balanced between the extremes of the "foundation

\footnotetext{
E. Bordogna $(\varangle) \cdot$ T. Brighenti

Architecture, Built Environment and Construction Engineering-ABC Department,

Politecnico di Milano, Milan, Italy

e-mail: enrico.bordogna@polimi.it 
city" of Gibellina Nuova (with Burri's wonderful invention of "The Great Cretto" in memory of the historical Gibellina) and more circumscribed interventions but of definite quality like those in Salemi; unquestionably less convincing, or explicitly negative, is the experience of the so-called "new towns", decentralized and of poor architectural quality, built after the earthquake in L'Aquila.

In the case of the earthquake in Central Italy in 2016, restricting the field to the municipalities of Norcia, Amatrice and Camerino, the diagnostic analysis and the reconstruction strategies were necessarily diversified. ${ }^{1}$ If, in Norcia, apart from the monumental buildings of the centre for which a philological restoration is anticipated, it would appear that the most urgent sector for reactivation and relaunching (with some similarities to the case of Friuli) is the widespread fabric of small commercial and production units linked to the agri-food sector; if in Amatrice, so dramatically affected that there is practically nothing left of the ancient nucleus, the most urgent exigency appears to be the reconstitution of a new urban centre consisting of civic services and residences, to complete an episode of valuable morphological definition and architectural buildings like the one carried out by Arnaldo Foschini between the 1930's and 1960's (a unitary complex with an orphanage, hospice and separate church); if in Camerino it seems that any intervention cannot neglect the important university and cultural structures present; in all three of the contexts examined, on the contrary, beyond these differentiated situations, the system of basic and secondary education has been hard hit, thus becoming a common priority field for reconstruction.

\section{Norcia. A Campus for Basic Education and Sports Facilities as a Part of the City}

At the end of 2016, around 800 pupils, from nursery to secondary school, found themselves deprived of the opportunity to take advantage of their school buildings which had been destroyed or seriously damaged by the seismic shocks. The existing school system had an arrangement that was markedly bipolar: one school complex located immediately beneath the ancient city walls, just outside the main gate from the territory to the Old Town, given over to an elementary school, a junior secondary, and a comprehensive series of sports facilities; a second complex, further north, in a valley just outside the walls, was entirely dedicated to secondary education (Classical, Scientific, and a Technical Institute for Surveyors).

\footnotetext{
${ }^{1}$ The essay being published here refers to research work executed, starting from the month of September 2016, within the Architectural Design Workshop of the Master Course of the School of Architecture, Urban Planning, Engineering of constructions (AUIC) of the Politecnico di Milano, in the academic years 2016-2017, 2017-2018, 2018-2019 (Professors Enrico Bordogna, Tommaso Brighenti, Vito Maria Finzi (Technology), Mauro Madeddu (Structures); with the collaboration of the newly graduated architects Marco Pinna, Silvia Faravelli, Marco Frisinghelli, and Nicolas Decima.
} 
Both complexes, while in the current post-earthquake state of compromise, are characterized by a plan that is approximately that of a "campus", with the individual school buildings for different levels and subjects interrelated and connected to the sports facilities and the surrounding green areas, to form structures that are morphologically unitary and integrated.

In particular, the lower schools, close to the main gate in the city walls, are characterized by the elementary school building, a typical C-shaped structure with two storeys from the late 1950's, aligned with the main thoroughfare to access the city from the surrounding territory with classrooms arranged in series along corridors overlooking the inner courtyard. A typology that was frequent at the time, evidently derived from pre-war school building, but featuring a clear layout and dignified architectural forms, with a pitched roof, pale plastered façades, and a regular and uniform pattern of openings.

Continuing upwards from one wing of the C-shaped building is another structure with three storeys above ground, and typical forms of the 1960s in unclad reinforced concrete, infill walls in brick and a gable roof, which houses the junior secondary school. In the open space delimited by these two buildings, in anonymous rectangular structures with only one storey above ground, a gym and other service spaces in a prefab are housed, while all around, in a richly wooded green environment characterized by repeated variations in height, are a large range of sports facilities open to the citizens in addition to school use, comprising a football pitch, tennis courts, and outdoor swimming pools with associated locker rooms.

All in all, a small, well-organized "campus for education and sport", probably built up over time without an explicit original design, but of undoubted quality and with its own identity, which the 2016 earthquake seriously maimed but did not completely destroy, although it did leave the elementary and junior secondary school buildings unusable.

With this scenario, the choice of this project was to confirm the layout of the existing campus with even greater force and a wealth of facilities. To this end, the elementary school building was restored, its plan and measurements being taken as the generating element of the proposed morphology, while the junior secondary school building was replaced since it was considered no longer recoverable, as were the small anonymous pavilions for the gym and related services (Figs. 1-2-3).

The two arms of the C-shaped elementary school building were extended with two in-line blocks interconnected by a path covered by a portico, the latter also acting as a retaining wall while delimiting the internal open space by creating a court in part left green, more reserved but intentionally permeable, so as to also function as a small urban square. Within this court, a small outdoor wooden theatre can accommodate dramatic and musical performances by the students, and other activities and events of the entire school complex and the community. In the wider in-line structure is the gym and a swimming pool, while in the narrower structure two storeys above ground house the junior secondary school. On the side of the $\mathrm{C}$-shaped building, facing south, lying along the internal pedestrian axis which crosses the whole of the campus, is a small school for infants including a nursery school and a crèche, with a 

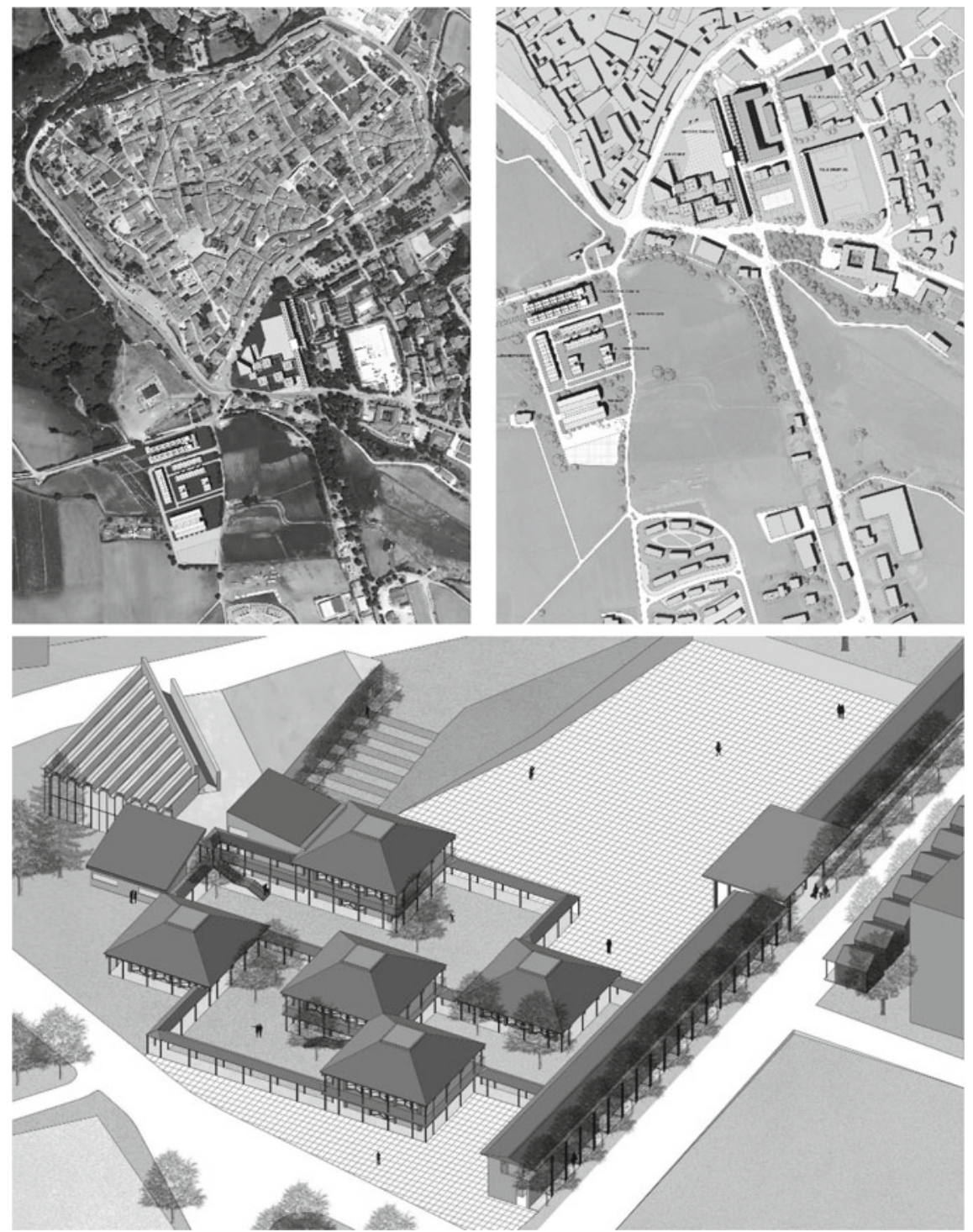

Fig. 1-2-3 Norcia: aerial photogrammetry with inserted project; plan; axonometry of the exhibition center and covered market (Students: V. Boffo, A. Bugatti, A. Sposetti, 2018)

square ground plan arranged around a small courtyard overlooked by the classrooms with communal outdoor spaces for the children to play. 
A possible variant of the project indulges in greater freedom than the existing situation, confirming the elementary school building but introducing above it an entrance plaza of an urban value, rhomboidal in shape, surrounded by three new buildings for the nursery school, junior secondary school and gym, in turn the object of more accentuated typological and expressive research. Also the sports facilities, occupying part of the football field area moved not far away, are more consolidated,

With more substantial indoor and outdoor amenities (gym, swimming pool, basketball, volleyball and tennis courts), with a stand, locker rooms, and other service areas for the public.

The principle common to both the solutions proposed is however the confirmation of the campus' layout, using the sloping orography of the site to make the area of the intervention visually attractive and more permeable since, being situated immediately outside the historical walls, it acts as a filter between the ancient compact fabric of the centre and the charming surrounding natural landscape which characterizes the Municipality of Norcia and its countryside. In this sense, in both solutions, the design brief, rather than investigating the internal typological configuration of the various school buildings, attempts to lay out a part of the city which is specifically intended for functions of education, sports and leisure, combined, beyond the historical access route from the territory, with the proposal of an intervention intended as a trade fair area (exhibition halls with a wooden structure, arranged in a grid and with square pyramidal pitched roofs) and an in-line block fronting the street, opposite the elementary school, intended for shops and market structures for the traditional local agri-food products (Figs. 4-5, 6, 7-8-9, 10-11-12).

\section{Amatrice. Hotelier Institute and Cooking School for a New Urban Centrality}

In Amatrice, the 2016 earthquake completely destroyed the Old Town (Fig. 13): all that currently remains is the central road axis which diagonally structured this typical ridge settlement from gate to gate, from west to east, regrettably now surrounded by flattened areas of rubble clearance that make the original morphology of the ancient centre unreadable. On the contrary, on the same axis to the west just outside the centre, we can still find, entirely recognizable despite the substantial damage suffered, the urban area created by Arnaldo Foschini ${ }^{2}$ between the 1930's and 1960's, a unitary complex with an orphanage, hospice and separate church, of a clear morphological

\footnotetext{
${ }^{2}$ In the early Twenties, Arnaldo Foschini created one of his first works for Amatrice, the Institute for War Orphans, built between 1921 and 1923 for the Opera Nazionale per il Mezzogiorno d'Italia, a building for 150 children and five other minor buildings for schools of art and crafts. At the same time, he was developing his project for the church, revised in 1938, interrupted because of the war and then brought to fulfilment in various phases until it was finally finished in 1961, enriched by numerous works of art, such as the large bas-relief in travertine of the façade. In the same years, also the large building of the hospice was completed, whose U-shaped plan and three storeys concluded the entire ground plan. See Pirazzoli (1979), pp. 86-89.
} 

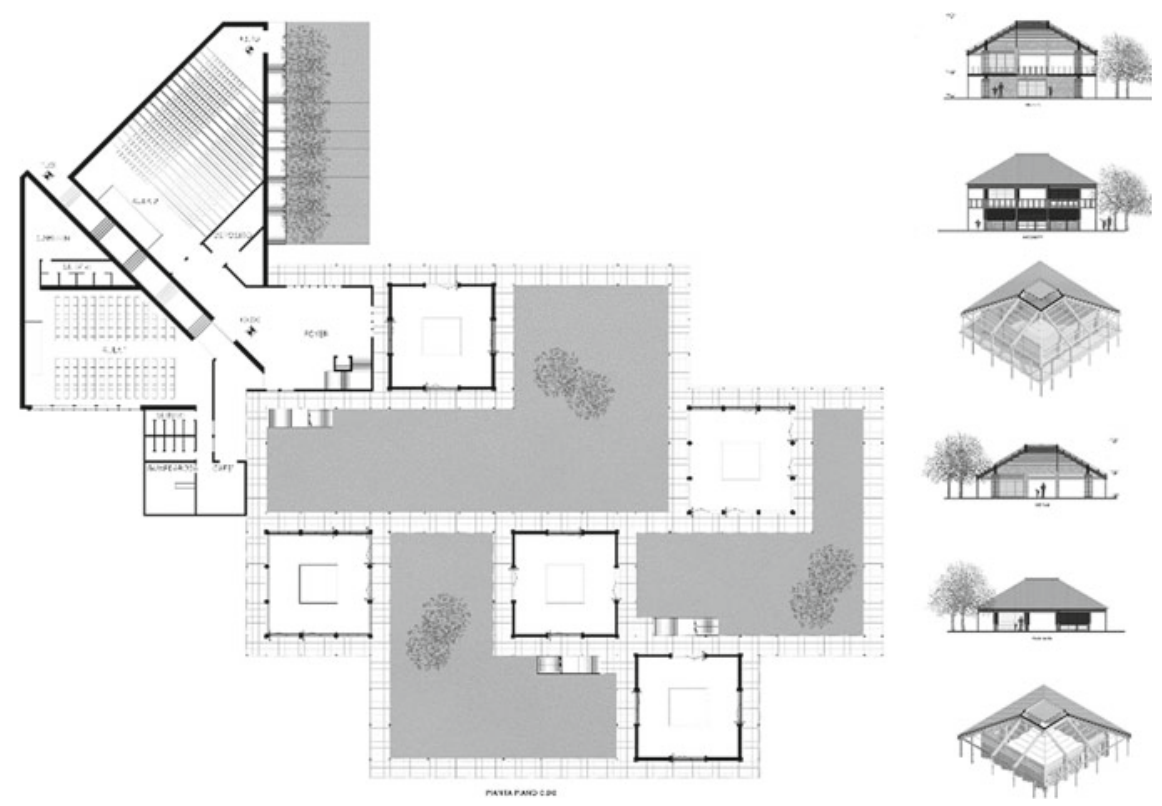

Fig. 4-5 Norcia: Trade fair plan; sections, elevations and axonometry of the pavilions (Students: V. Boffo, A. Bugatti, A. Sposetti 2018)

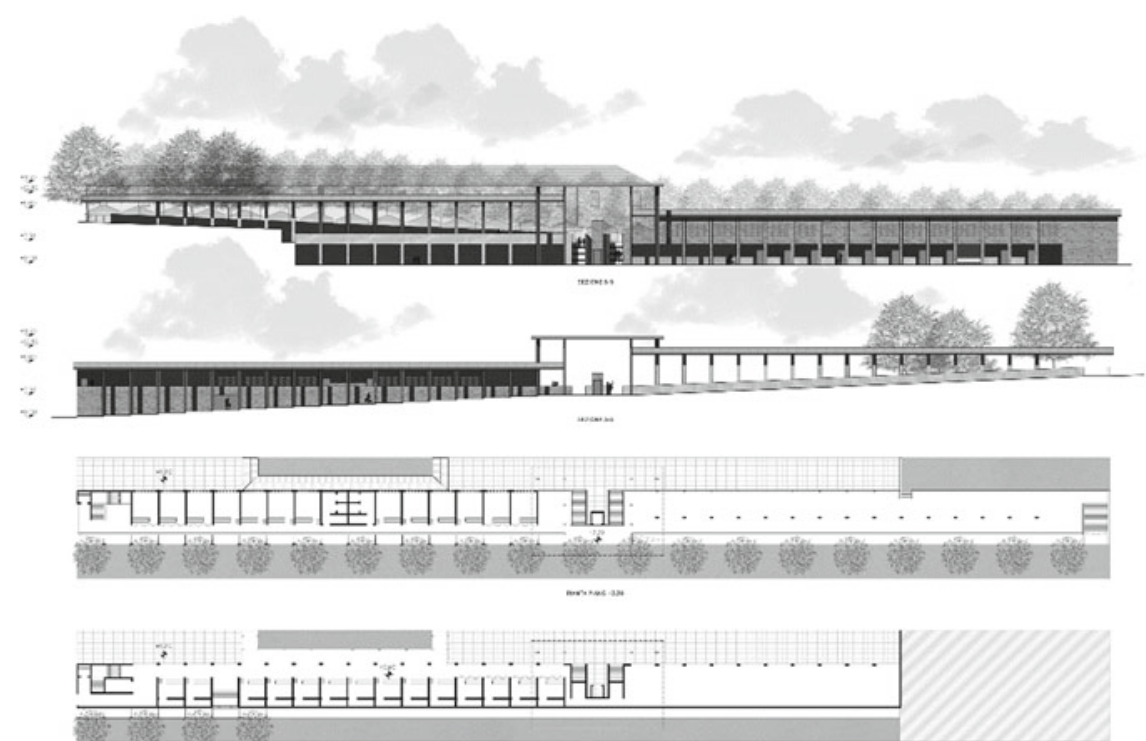

Fig. 6 Norcia: plans and elevations of the covered market (Students: V. Boffo, A. Bugatti, A. Sposetti 2018) 

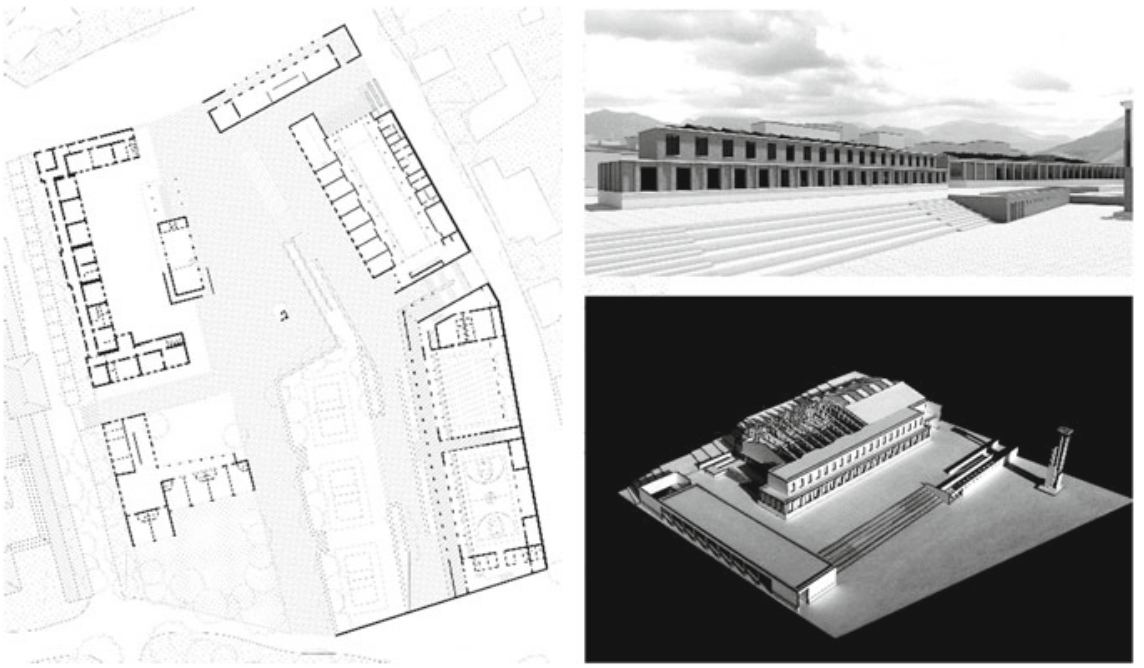

Fig. 7-8-9 Norcia: plan of the school campus; perspective view of the kindergarden; photo of the model (Students: M. Colombo, P. Escoriza, M. Iotti 2019)
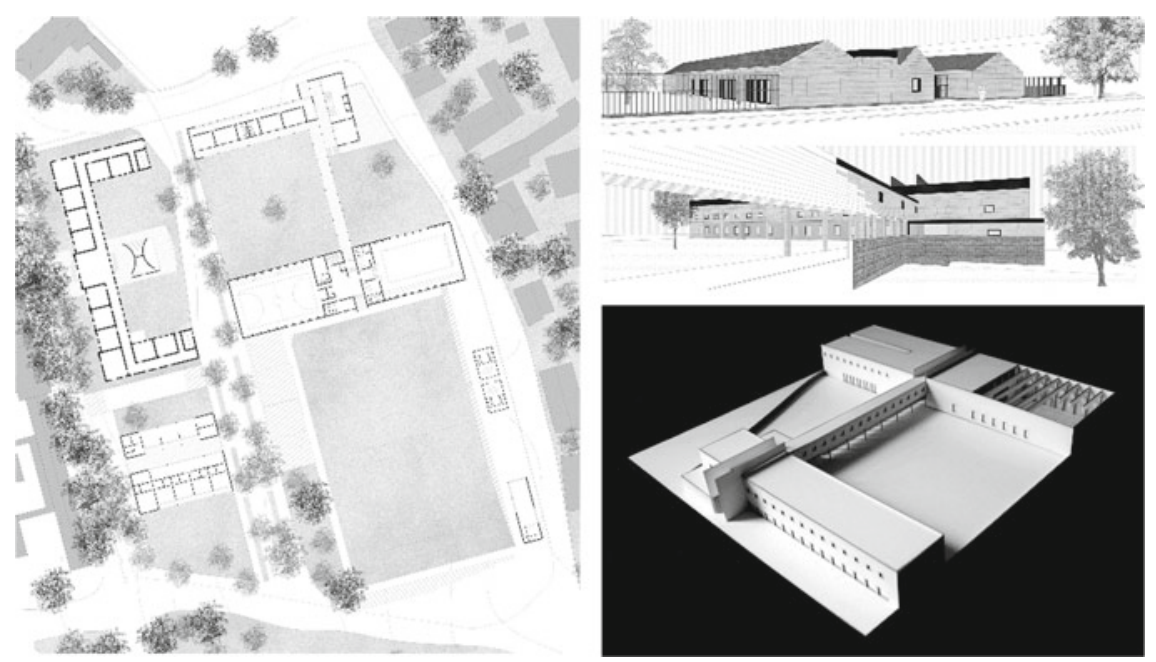

Fig. 10-11-12 Norcia: plan of the school complex; perspective view of the asylum and school building; model photo (Students: S. Angeli, S. Angrilli 2019) 

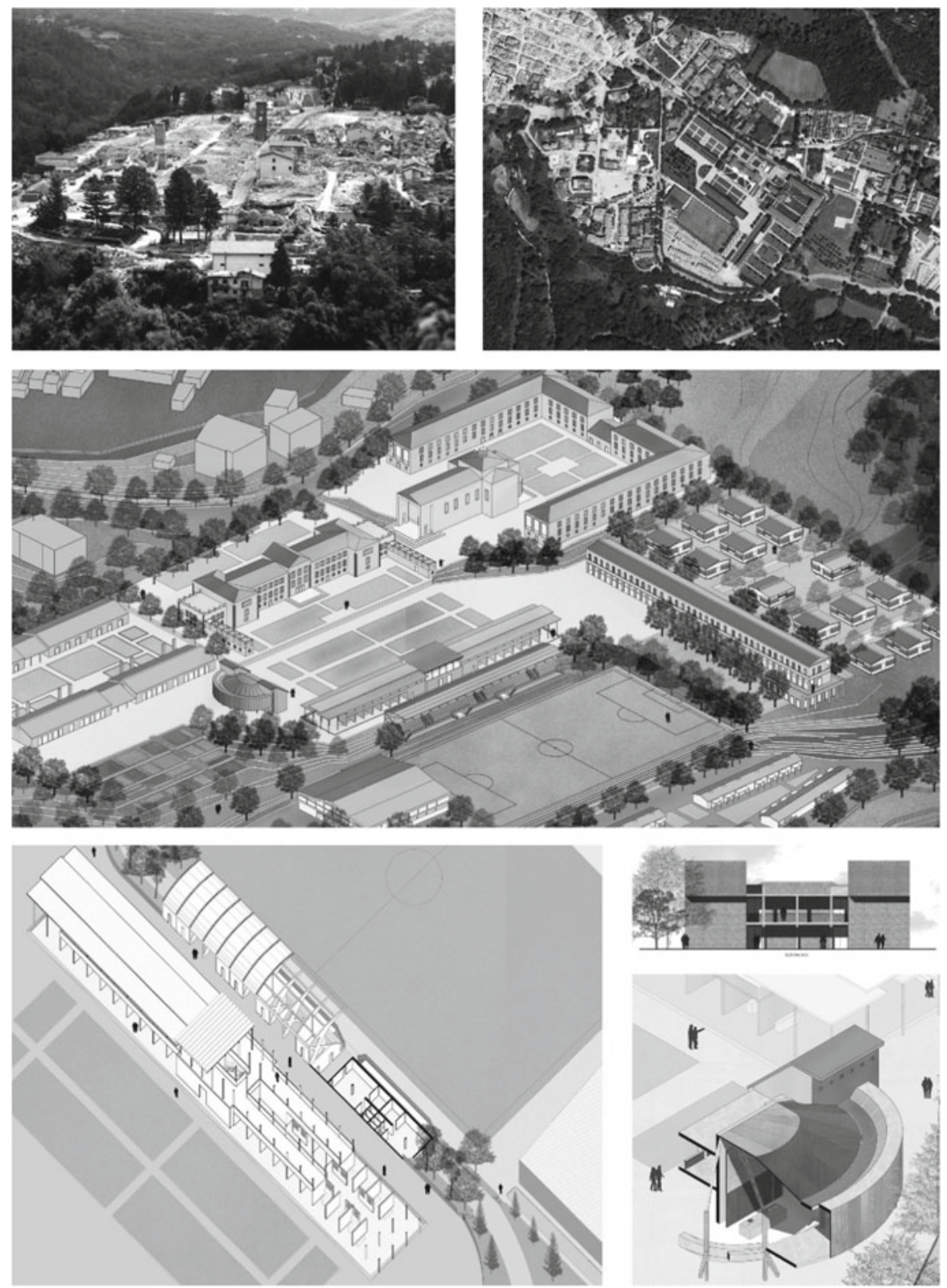

Fig. 13-14-15-16-17 Amatrice: view of the municipality after the 2016 earthquake; aerial photogrammetry with the design of public buildings to complete the urban section created by Arnaldo Foschini; general project axonometry; axonometric cutaway of the covered market; elevations and axonometric cutaway of the "anatomical" theater of the cooking school (Students: L. Bongiolatti, A. Giamboni, C. Landoni 2018) 
definition and a sober expressive quality, to which a series of other facilities including a football pitch and an indoor gym was subsequently added lower down, on an orography characterized by significant changes in height. Instead, between the old nucleus and Foschini's complex, the buildings of an elementary school and a hotel school that was important for the economy of Amatrice were entirely destroyed. The hotel school, which was attended by around one hundred and thirty students, mostly from outside the town and the province, has been temporarily transferred to Rieti after the earthquake. In the same way, in a contiguous area, four simple pavilions arranged parallel, with one storey above ground, which once served as barracks, were totally destroyed.

In this scenario, by resorting to certain Muratori-style antecedents, in particular the square of the Cortoghiana workers' centre in the mining district of south-west Sardinia, the project has focused on configuring a new urban centrality, arranging,

in correspondence with Foschini's buildings now restored and given new destinations (a municipal seat in the former orphanage, healthcare services and special residences for the elderly, students, and young couples in the former hospice), two orthogonal squares arranged as an "L", with, on the one side, an in-line block with two and three floors for council housing overlooking the piazza sloping down towards the valley, a portico on the ground floor and continuous eaves, and, on the opposite side, near the area of the former barracks, the hotel and cookery school, as an ideal extension and completion of Foschini's scheme. Meanwhile, on the side towards the valley overlooking the former orphanage, there is a double in-line block for commercial use, with below it a stand and changing rooms for the existing sports field. In Amatrice, as in Norcia, in the project (and also in the successive variations) what has prevailed is the attention to the urban dimension of the intervention rather than a specific typological investigation of school building. Arguably, the only exception is the cookery school. In this case, the plan of the former barracks pavilions was reused, with teaching spaces and external roofed environments for services and a restaurant, but for the specific needs of a cookery school a new building was inserted, in front of Foschini's church but isolated from it, and with a central plan that incorporates the evocative typology of the anatomical theatre, here reconverted for culinary education (Figs. 14-15-16-17).

\section{Camerino: Rescue, Recovery and Restoration of Works of Art Affected by the Earthquake}

In Camerino, the project sought to address a single theme, but equally important, that of rescuing, recovering and restoring works of art affected by the earthquake, also in consideration of the presence at the local university of a course of studies in Cultural Heritage with which to establish useful synergies of mutual exchange, involving the students in the laboratory work and internships for the restoration of works of art or research into local art. 
This has resulted in an original typology, conditioned on the one hand by the particular characteristics of the context and designed on the other hand to match educational and museum/laboratory needs.

The choice was to intervene outside the Old Town, today only partially accessible, consolidating with the new addition, a complex consisting of buildings for a university residence and a departmental library created at the beginning of the 2000s by the architect Raffaele Mennella. ${ }^{3}$

On a gentle slope, north of the Old Town, the project envisages three linear blocks opening into a trident, which climb the contours of the hilly terrain in continuity with the existing university residences. The enclosed green areas that link the various parts of the intervention in a system of public and collective spaces, designed to enhance the characteristics of the site, overlook the landscape of the Esino Valley, towards the Primo and San Vicino mountains.
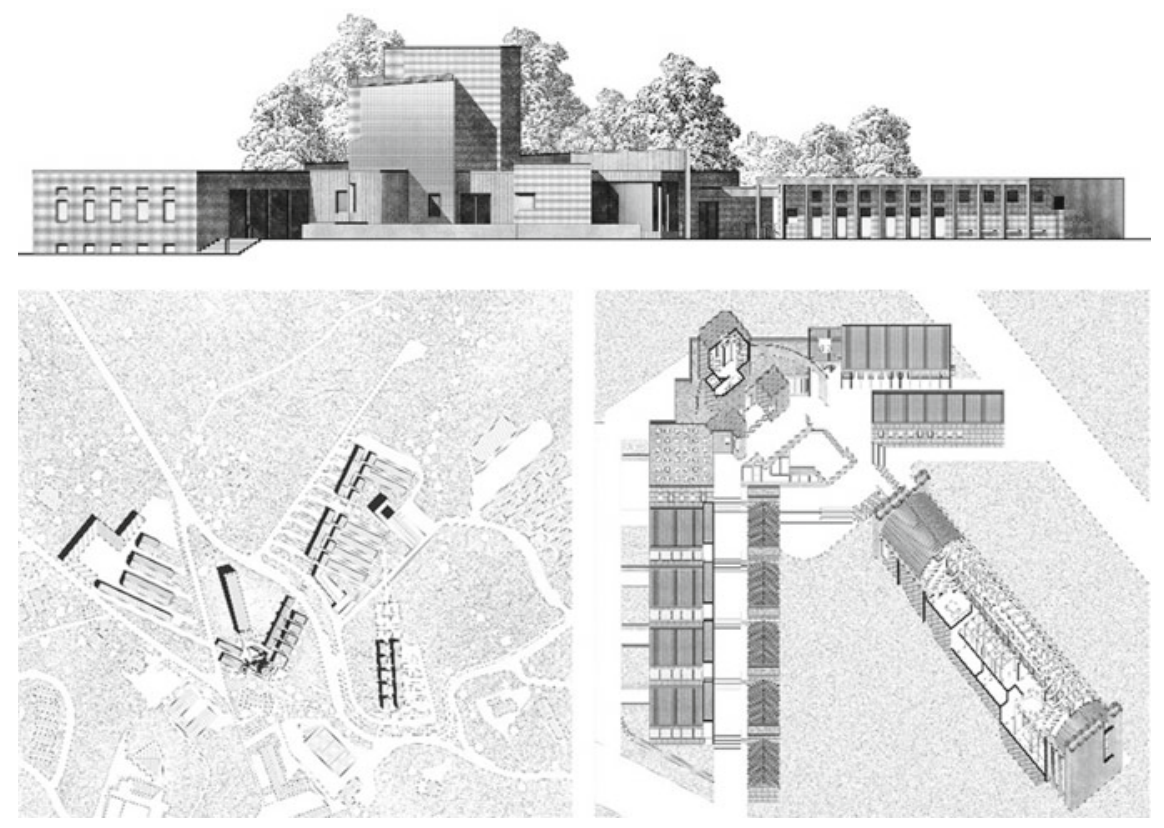

Fig. 18-19-20 Camerino: Center for the recovery and restoration of cultural assets affected by the earthquake, internal elevation, plan, axonometric cutway (Students: S. Faravelli, M. Frisinghelli, Graduation 2019)

\footnotetext{
${ }^{3}$ The project area is located at the end of Via Madonna delle Carceri, in the north of Camerino. This trajectory arises inside the centre from the main street that runs through the historical settlement and which, near the Museum of San Domenico, splits in two to define the main axes of the town's suburbs. Past the university's science centre, the Church of Madonna delle Carceri and the commercial area of the supermarket, the trapezoidal-shaped zone chosen lies strategically at the end of the sequence of statements positioned along this trajectory.
} 
The three buildings have separate destinations. The first wing, in continuity with the existing university residences and in turn split, houses standard university functions: teaching, research, work spaces for students; the central wing is given over specifically to a museum, with rooms for storage, restoration workshops, exhibition spaces for works salvaged from the territory; the third wing, of smaller dimensions and facing towards the recently constructed shopping mall, houses the service structures, with spaces for local associations, offices, a projection room, and a hostel.

The three in-line buildings converge in a sort of slab that is articulated in plan and elevation, whose underground floor is intended for the deposit of works of art awaiting restoration, while the roof is a public square at the service of the entire complex. At the summit of the slab is a tower with a composite disposition of the masses, containing a specialist library and complementary service spaces, acting as a formal hub of the whole design, configuring a systematically concluded intervention that is centroidal with respect to the existing university structures (Figs. 18-19-20).

\section{Reference}

AA.VV (1979) Atti del Convegno. Arnaldo Foschini. Didattica e gestione dell' architettura in Italia nella prima metà del Novecento, Pirazzoli N (ed), Faenza Editrice, Faenza

Open Access This chapter is licensed under the terms of the Creative Commons Attribution 4.0 International License (http://creativecommons.org/licenses/by/4.0/), which permits use, sharing, adaptation, distribution and reproduction in any medium or format, as long as you give appropriate credit to the original author(s) and the source, provide a link to the Creative Commons license and indicate if changes were made.

The images or other third party material in this chapter are included in the chapter's Creative Commons license, unless indicated otherwise in a credit line to the material. If material is not included in the chapter's Creative Commons license and your intended use is not permitted by statutory regulation or exceeds the permitted use, you will need to obtain permission directly from the copyright holder.

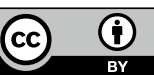

